\title{
REGIONALIZMY W PRZEKŁADZIE NA PODSTAWIE TŁUMACZEŃ NIEMIECKO-POLSKICH
}

Zarys treści: Artykuł poświęcony jest problemowi tłumaczenia regionalizmów (gwara, regionalizmy ponadgwarowe, standardy wariantów narodowych w przypadku języków pluricentrycznych). Wyrażenia gwarowe i regionalne ponadgwarowe można w zasadzie przetłumaczyć tylko na język standardowy. Rożnie tłumaczyć należy nazwy urzędów i instytucji poszczególnych krajów niemieckojęzycznych.

$\mathrm{T}_{\mathrm{s}}$ ylko część języków ma jeden standard (język monocentryczny, np. litewski), inne języki mają charakter policentryczny (więcej niż jeden standard). Warunkiem określenia danego języka jako pluricentrycznego nie jest więc używanie go w więcej niż jednym kraju, lecz istnienie przynajmniej dwóch standardów narodowych. Do indoeuropejskich języków pluricentrycznych zaliczane są np. angielski, niemiecki, francuski, hiszpański, portugalski. (por. Clyne 1992). Język niemiecki ma teoretycznie trzy równoważne standardy:

- standard niemiecki, zwany po niemiecku najczęściej Bundesdeutsches Hochdeutsch albo Bundesdeutsch, wcześniej Binnendeutsch;

- specyficzne wyrażenia i formy gramatyczne tego wariantu narodowego języka niemieckiego nazywa się teutonizmami (Deutschlandismus, Bundesgermanismus Teutonismus). Norma językowa zawarta jest w serii Duden;

- standard austriacki, zwany po niemiecku Österreichisches Deutsch, rzadziej Österreichisch. Jest to standard rodzący się bardzo długo, gdyż już od czasów cesarza Maksymiliana I. Podstawową przyczyną jego powstania była chęć przynajmniej częściowego zerwania ze stan- 
dardem niemieckim. Najważniejszym efektem tych poczynań jest Österreichisches Wörterbuch. Standard ten - w przeciwieństwie do standardu niemieckiego - nie jest w pełni opisany, tzn. nie ma kompletu prac go opisujących (por. seria Duden w standardzie niemieckim). Typowe zjawiska i formy tego standardu nazywamy austriacyzmami,

- standard szwajcarski, zwany po niemiecku Schweizer Hochdeutsch. Standardu tego nie należy mylić ze Schweizerdeutsch (Schwyzerdütsch), czyli językiem potocznym bazującym na dialektach alemańskich używanych w Szwajcarii niemieckojęzycznej. Schweizer Hochdeutsch nazywany bywa też Schweizer Schriftdeutsch, gdyż pojawia się on w zasadzie tylko w języku pisanym. Nawet wykłady na uniwersytetach odbywają się $\mathrm{z}$ reguły $\mathrm{w}$ języku potocznym. Szwajcarzy zawsze odczuwali niechęć do języka używanego przez Niemców, a wcześniej także języka Austriaków. Tworzenie własnego standardu dla języka niemieckiego - dialektami tego języka mówi ponad 63\% mieszkańców tego kraju - nie było konieczne, gdyż w kontaktach z zagranicą używano i używa się głównie języka francuskiego. Stąd też w standardzie tym pojawiają się w Szwajcarii w zasadzie tylko materiały dla uczniów.

Nadmienić należy, że w drugiej połowie XX wieku doszło do częściowego podziału standardu niemieckiego na standard zachodnio- i wchodnioniemiecki. Obydwa miały swoją nieco odmienną normę. Standard wchodnioniemiecki wytworzył się głównie na płaszczyźnie języka oficjalnego. Był to swego rodzaju żargon (slang) używany głównie w środkach masowego przekazu oraz na oficjalnych zebraniach. Do języka codziennego przebijały się oczywiście pewne wyrażenia, ale tylko w ograniczonym zakresie. Jest stwierdzone jednoznacznie, że obywatel NRD posługiwał się bardzo często dwoma wariantami języka - oficjalnym w miejscach oficjalnych i prywatnym w domu. Idea Waltera Ulbrichta, zaszczepiona mu przez Józefa Stalina, że powstanie nowy naród, z nową kulturą, z nową świadomością i nowym językiem, nie mogła zostać zrealizowana, gdyż codzienne kontakty między tymi wariantami języka niemieckiego - choćby przez dostępność mediów elektronicznych i wizyty krewnych - uniemożliwiały pełną izolację obywateli NRD.

Innym lektem, czyli odmianą języka niemieckiego, są dialekty/gwary. W przeciwieństwie do Polski, gdzie władzom komunistycznym udało się skutecznie zasugerować, że mówienie dialektem świadczy o prymitywności, posługiwanie się gwarą nie uchodzi w krajach niemieckojęzycznych za gorszy sposób komunikowania się, szczególnie na obszarze górnoniemieckim. Dia- 
lekty północnoniemieckie (szlezwicki, holsztyński, dolnosaksoński, westfalski, ostfalski, meklemburski, brandenburski, pomorski) uległy prawie całkowitemu zanikowi, co nastąpiło głównie pod wpływem języka Lutra (wariant wchodnio-środkowo-niemiecki, dokładnie górnosaksoński), czyli języka konfesji ewangelickiej przejmowanej przez kraje północnoniemieckie. Język ten najpierw przyjął się w kancelariach, potem $w$ innej korespondencji oraz literaturze i w końcu w kontaktach codziennych. Dzisiaj mamy resztki tych dialektów, które możemy określić jako swego rodzaju folklor.

Utrzymały się natomiast dialekty środkowoniemieckie wspierane przez Kościół ewangelicki, dalej władców Saksonii i Prus, oraz dialekty górnoniemieckie jako język katolików (kontrreformacji) oraz Habsburgów i innych władców z południa obszaru języka niemieckiego (np. Witelsbachowie). Przyczyniło się też do tego utworzenie na części tego terenu odrębnych państw, czyli państwa austriackiego - najpierw Cesarstwa Austriackiego (1804-1867), potem Austro-Węgier (1867-1918) i w końcu Republiki Austriackiej (od 1918, z małą przerwą w latach 1938-1945) oraz Szwajcarii (niepodległy byt polityczny od roku 1648).

Między dialektami/gwarami i językiem standardowym istnieją warianty regionalne i wiążące się z nimi warianty języka potocznego. Liczba wariantów regionalnych jest mała. Swój wyraz znajdują one przede wszystkim na płaszczyźnie leksykalnej. Sprzeciwu nie budzi wyróżnianie takich wariantów regionalnych, jak (przykłady za König 1998: 192-229):

- północnoniemiecki - a) Knirk/Machangel, b) Rotkohl, c) Pötter,

- środkowoniemiecki - a) Wacholder, b) Rotkraut, c) Töpfer,

- południowoniemiecki - a) Kranawit(t), c) Blaukraut, c) Hafner.

Mamy więc w przypadku obszaru języka niemieckiego do czynienia $\mathrm{z}$ trójpodziałem na standardowe warianty narodowe, warianty regionalne i dialekty.

W przypadku języka polskiego paleta ta jest znacznie skromniejsza. Język polski jest językiem monocentrycznym i nie ma wariantów/standardów narodowych. Pewne problemy pojawiają się przy odgraniczeniu regionalizmów od dialektyzmów. Podawane w słownikach definicje nie są jednoznaczne. Zgodzić się można z Walerym Pisarkiem (1992: 282 f.), że dialektyzm to gwaryzm, czyli element językowy występujący w danej gwarze, natomiast regionalizm to element językowy używany na części obszaru danego języka, przy czym należy dodać, że obejmuje on obszar większy niż jedna gwara.

Sytuacja gwar w Polsce jest zdecydowanie inna niż w krajach niemieckojęzycznych. Wskazują na to cząstki definicji Walerego Pisarka (1992: 283): 
regionalizmy, w przeciwieństwie do form dialektalnych i gwarowych, występują również w mowie warstw wykształconych, np. w Warszawie mówi się kartofle, w Krakowie - ziemniaki, a w Poznaniu - pyrki

\section{i Zygmunta Saloniego (2003: 485):}

występując [...] w języku ogólnym, w przeciwieństwie do form dialektalnych i gwarowych, r[egionalizmy] występują także w języku ludzi wykształconych.

Otóż gwary polskie przeżyły po II wojnie światowej okres bardzo trudny z przyczyn ideologiczno-politycznych. Pierwszym celem była likwidacja gwar kresowych. Aby tego dokonać:

- nie zezwalano na zajmowanie przez przedstawicieli danej gwary jednego obszaru,

- w sposób pośredni i bezpośredni ośmieszano osoby mówiące gwarą jako ludzi prymitywnych, co odbija się w definicjach Pisarka i Saloniego.

W drugim przypadku dodatkowym celem była likwidacja gwar z obszaru dawnego zaboru pruskiego (np. Wielkopolska, Śląsk). Respektowane w pewnym zakresie były gwary warszawska i w mniejszym stopniu krakowska jako gwary miejskie (folklor miejski).

Nie do pomyślenia było i jest, by nauczyciel w szkole czy wykładowca na uczelni mówił gwarą lub nawet językiem potocznym o nachyleniu gwarowym, co na obszarze środkowo- i górnoniemieckim jest codziennością.

Dopiero w ostatnich latach nastąpiło pewne dowartościowanie gwar, szczególnie śląskiej (TV Silesia), ale także wielkopolskich (gwara poznańska). W oświacie mówi się - w zasadzie pod wpływem Unii Europejskiej - o edukacji regionalnej. Zasadniczą rolę mają tutaj odgrywać folklor i literatura regionalna.

W Polsce odróżnia się następujące podstawowe obszary dialektalne: małopolski, wielkopolski, mazowiecki, śląski i obszar nowych dialektów mieszanych.

W przypadku języka polskiego odróżniamy więc również trzy płaszczyzny:

- jeden język standardowy bez wariantów narodowych,

- regionalizmy (słabo rozbudowane),

- dialektyzmy/gwary (zepchnięte do roli języka codziennego ludzi niewykształconych, nawet prymitywnych, i przez to zanikającego, oraz ozdobników stylistycznych). 
Językoznawstwo polonistyczne ma pewne kłopoty ze zdefiniowaniem regionalizmu. Duża część polonistów zalicza do regionalizmów wszystkie zjawiska, które nie są używane na całym obszarze języka polskiego - np. gwary miejskie (krakowska, poznańska, warszawska), dialektyzmy (śląskie grule, wielkopolskie pyrki) oraz ponaddialektalne regionalizmy (na szagę/siage - na skuśkę; na polu - na dworze/na dworzu).

Nie ma w Polsce w zasadzie typowej literatury gwarowej, pojawia się tylko stylizacja gwarowa, która opiera się na użyciu elementów gwary w dziełach literackich pisanych w języku standardowym (por. Wesele Stanisława Wyspiańskiego, Chłopi Władysława Reymonta) czy też przykładowo filmach fabularnych i serialach Sól ziemi czarnej, Perła w koronie, Czterej pancerni i pies, Dom itd.

$\mathrm{W}$ języku niemieckim nawet $\mathrm{w}$ istniejących szczątkowo gwarach dolnoniemieckich wydaje się wiele dzieł literackich. Jeden tylko Schribi-Verlag proponuje w chwili obecnej kilkadziesiąt pozycji. Jako przykład wymienić można dzieła Güntera Schnedemanna i Karla-Ernsta Galla, piszących w gwarach dolnoniemieckich:

- De Tiet blifft nich stohn Güntera Schmedemanna,

- De Klock wiest uns de Tiet Güntera Schmedemanna,

- Dat Siedlungshus Güntera Schmedemanna,

- Hett allens siene Tiet Güntera Schmedemanna,

- Gefohren luern överall Karla-Ernsta Galla,

- Plattdütsch Blaumen Karla-Ernsta Galla i innych,

- Späuken ut Vörpommern Platt Karla-Ernsta Galla.

Zajmujący się tłumaczeniami z języka niemieckiego na polski i odwrotnie znajdują się w pewnych momentach w sytuacji bez wyjścia. Następuje to w przypadku tłumaczenia gwarowej literatury pięknej z gwar niemieckich na polski i stylizowanej gwarowo literatury polskiej na język niemiecki. Nie ma możliwości przełożenia literatury gwarowej na gwarę innego języka. Niemiecką literaturę gwarową przełożyć możemy tylko na polski język standardowy. W tym przypadku literatura ta traci swój folklor. Świadomi tego tłumacze nie podejmują się w przypadku literatury niemieckojęzycznej przekładów dzieł pisanych w gwarach. Podobnie ma się sprawa ze regionalizmami, których też nie można przekładać na regionalizm w drugim języku, gdyż czyniłoby to np. z mieszkańca Małopolski mieszkańca południowych Niemiec. $\mathrm{Z}$ drugiej strony nie ma czegoś takiego jak język regionalny, są tylko regionalizmy na płaszczyźnie leksykalnej i gramatycznej. W przeciwieństwie do literatury gwarowej tłumacz musi tutaj sam znaleźć regionalizm lub dialektyzm w tłumaczonym przez siebie tekście. W tym kontekście ważne są informacje 
uzyskane przez tłumacza z omówień danego dzieła oraz jego dotychczasowa wiedza.

Pierwszy sygnał dla tłumacza, że może mieć do czynienia ze zwrotem/ /słowem o charakterze regionalnym, pojawia się gdy nie rozumie on danego słowa i nie może go znaleźć w słownikach dwu-, a nawet jednojęzycznych. Dzisiaj ma jeszcze do dyspozycji Internet. Kiedyś tego tłumacz nie miał. W opowiadaniu Strittmattera Die blaue Nachtigall znajdujemy m.in. trzy następujące zdania

Die Mutter betrieb im Kotten an der Lanstraße eine Nähwerkstatt, [...] - s. 8

Die Wohnstube des Kottens an der Lanstraße nach Schlesien war die Szenerie, in der ich für mein jetziges Leben erwachte. - s. 8

Die Wohnstube im Kotten an der Landstraße nach Schlesien war Schneiderwerkstatt, Kurzwarengeschäft und Kinderspielplatz in einem. - s. 9

Tłumacz - koniec lat siedemdziesiątych - nie poradził sobie ze słowem Kotten i pomimo wyraźnego wskazania przez użycie im, że nie może to być nazwa miejscowości, przetłumaczył to słowo jako toponim:

Matka prowadziła w Kotten przy trakcie krawiecki warsztat, [...] - s. 7

Izba mieszkalna $w$ Kotten przy trakcie na Śląsk stanowiła scenerię, $w$ której przyszedłem na świat. - s. 7

Izba $w$ Kotten przy trakcie na Śląsk stanowiła warsztat krawiecki, sklepik z towarami pasmanteryjnymi i miejsce dziecięcych zabaw. - s. 8

A Kotten, Kote, Kot, Koth(e), Kott/e/n czy Kotze to po prostu chata w gwarach północno- i wchodnio-środkowo-niemieckich.

Pojawiają się jednak bardziej znane regionalizmy lub wyrażenia gwarowe, jak np. bawarsko-austriackie Grüß Gott. Niestety, nie ma w polskim pełnego odpowiednika tego pozdrowienia. Jak więc przetłumaczyć tytuł satyrycznego filmu Grüß Gott, Genosse. Nie ma w zasadzie innego wyjścia, jak zastosować standardowe Szczęść Boże (taka jest też propozycja podręcznego słownika niemiecko-polskiego), choć temu Szczęść Boże odpowiada w języku niemieckim właściwie Gott segne dich. Tytuł filmu przetłumaczono jako Szczęść Boże, towarzyszu. Tłumacz wskazał na to, że mamy tutaj do czynie- 
nia z czerwonym towarzyszem (nauczyciel), który przemienia się w chrześcijanina. Tracimy jednak wskazówkę, że po zmianach znalazł się w ultrakatolickiej Bawarii.

I inny przykład. W dyskusji o domowych metodach leczenia użyte zostało przysłowie

Iss Kranawitt und Bibernell, dann sterbt Ihr nicht so schnell.

W tym przypadku możemy założyć, że użycie Kranawitt w wypowiedzi tego człowieka nie ma charakteru stylizacji regionalnej i możemy w tłumaczeniu użyć odpowiednika ze standardowego języka niemieckiego Wacholder, czyli jałowiec. W przypadku gdyby stylizacja była wskazana, można by użyć regionalizmu kadyk. Nie byłoby to pociągnięciem złym, gdyż nazwy tej używa się m.in. w nowych dialektach mieszanych, czyli nie jest ono przypisane bezwarunkowo do jednej ze starych gwar. Tłumaczenie bez użycia regionalizmów wydaje się jednak całkowicie do przyjęcia, np.

Jedz biedrzeniec i jałowiec, a zachowasz zdrowie.

Jedzcie biedrzeniec i jałowiec, a zachowacie zdrowie.

Podobne problemy będziemy mieli z oddanie regionalnego charakteru takich słów jak np.

\begin{tabular}{|l|l|l|}
\hline \multicolumn{1}{|c|}{ Północnoniemiecki } & \multicolumn{1}{c|}{ Południowoniemiecki } & \multicolumn{1}{c|}{ Polski standardowy } \\
\hline Streichholz & Zündholz & zapałka \\
\hline Sahne & Rahm & śmietana \\
\hline Pilz & Schwamm & grzyb \\
\hline Meeretich & Kre(e)n & chrzan \\
\hline Mütze & Kappe & czapka \\
\hline Hefe & Germ & drożdże \\
\hline
\end{tabular}

Są też specyficzne wspólne słowa/nazwy dla Austrii i Szwajcarii:

\begin{tabular}{|l|l|l|}
\hline \multicolumn{1}{|c|}{ Szwajcaria/Austria } & \multicolumn{1}{c|}{ Niemcy } & \multicolumn{1}{c|}{ Polska } \\
\hline die Matur/die Matura & das Abitur & matura \\
\hline die Faktura & $\begin{array}{l}\text { die Rechnung, } \\
\text { der Lieferschein }\end{array}$ & $\begin{array}{l}\text { faktura, rachunek, } \\
\text { dowód dostawy }\end{array}$ \\
\hline
\end{tabular}




\begin{tabular}{|l|l|l|}
\hline der Hausgang & der Hausflur & sień \\
\hline der Nationalrat & der Bundestag & $\begin{array}{l}\text { niższa izba parlamentu, } \\
\text { Rada Narodowa (mylące), } \\
\text { bundestag }\end{array}$ \\
\hline
\end{tabular}

Tłumacz ma w przypadku stylizacji ma problemy przede wszystkim wtedy, gdy użycie danego regionalizmu wiąże się w jakikolwiek sposób z cechami danej osoby, jej charakterem, przynależnością do grupy regionalnej itd. Możemy spróbować dopisać pewien komentarz, np.

Gruß Gott! - sagte Anton.

Juten Morjen - entgegnete der Verkäufer.

Oddanie tego dialogu jest stosunkowo trudne, ale można spróbować:

Dzień dobry - powiedział Anton po bawarsku.

Dzień dobry - odparł sprzedawca po berlińsku.

Dodatkowe wyjaśnienia mówią jednak dużo tylko tym, którzy mają wiedzę na temat różnic między Bawarczykami, którzy zdaniem berlińczyków nie są Niemcami, a berlińczykami, którzy uważani są przez Bawarczyków za Prusaków. Aby wszystko było jasne, należałoby w tym przypadku dać odsyłacz i umieścić na dole strony obszerny komentarz wyjaśniający.

Pozostaje nam jeszcze sprawa wariantów narodowych. Na tej płaszczyźnie musimy zdawać sobie sprawę między słownictwem terminologicznym/ /oficjalnym, czyli nazwami instytucji, oraz słownictwem z życia codziennego. W przypadku słownictwa codziennego są to słowa i struktury gramatyczne, które zostały na danym obszarze uznane za standardowe. Słowa te dadzą się podzielić na słowa specyficzne dla danego wariantu (teutonizmy, austriacyzmy, helwetyzmy) oraz słowa o specyficznym regionalnym znaczeniu, używane w różnym znaczeniu w różnych standardach.

Słowa specyficzne dla danego wariantu traktujemy tak samo jak inne regionalizmy. Nie ma tutaj problemu z ich rozpoznaniem, gdyż w innych standardach ich nie ma, a w dobrych słownikach znajdziemy odpowiednie wskazówki. Oto kilka przykładów dla standardu austriackiego i szwajcarskiego:

a) austriacyzmy

\begin{tabular}{|l|l|l|}
\hline \multicolumn{1}{|c|}{ Standard austriacki } & \multicolumn{1}{|c|}{ Standard niemiecki } & \multicolumn{1}{c|}{ Język polski } \\
\hline die Blunze & die Blutwurst & kaszanka \\
\hline
\end{tabular}




\begin{tabular}{|l|l|l|}
\hline das Eiklar & das Eiweiß & białko z jajka \\
\hline der Feber & der Februar & luty \\
\hline die Fisole & grüne Bohne & zielona fasolka \\
\hline der Karfiol & der Blumenkohl & kalafior \\
\hline der Paradeiser & die Tomate & pomidor \\
\hline der Powidl & die Zwetschkenmarmelade & powidła \\
\hline die Ribisel & die Johannisbeere & porzeczka (świętojanka) \\
\hline
\end{tabular}

b) helwetyzmy

\begin{tabular}{|l|l|l|}
\hline \multicolumn{1}{|c|}{ Standard szwajcarski } & \multicolumn{1}{|c|}{ Standard niemiecki } & \multicolumn{1}{c|}{ Język polski } \\
\hline der Anken & die Butter & masło \\
\hline der Büezer & der Arbeiter & robotnik \\
\hline das Büsi & die Katze & kot \\
\hline die Dähle & die Föhre & sosna (zwyczajna) \\
\hline das Gitzi & das Zicklein & kózka \\
\hline die Glätterin & die Büglerin/Plätterin & prasowaczka \\
\hline die Hausräuke & die Einweihungsfeier & $\begin{array}{l}\text { przyjęcie z okazji nowego } \\
\text { mieszkania, domu itd., } \\
\text { parapetówka }\end{array}$ \\
\hline der Meien/Maien & der Blumenstrauß & bukiet kwiatów \\
\hline
\end{tabular}

Znacznie trudniejszą sprawą dla tłumacza jest wychwycenie słów, które mają taką samą formę, ale inne znaczenie, czyli ze swego rodzaju fałszywymi przyjaciółmi tłumacza. Poniżej kilka przykładów słów o innym znaczeniu w standardzie austriackim i szwajcarskim niż w standardzie niemieckim:

a) austriacko-niemiecki

\begin{tabular}{|l|l|l|l|}
\hline \multicolumn{1}{|c|}{ Słowo } & $\begin{array}{c}\text { Znaczenie w stan- } \\
\text { dardzie niemieckim }\end{array}$ & $\begin{array}{c}\text { Znaczenie w stan- } \\
\text { dardzie austriackim }\end{array}$ & $\begin{array}{c}\text { Słowo niemieckie } \\
\text { dla znaczenia } \\
\text { austriackiego }\end{array}$ \\
\hline der Sessel & fotel & krzesło & der Stuhl \\
\hline der Kasten & skrzynia & szafa & der Schrank \\
\hline der Katalog & katalog & $\begin{array}{l}\text { katalog, dziennik } \\
\text { szkolny }\end{array}$ & $\begin{array}{l}\text { der Katalog, das Klas- } \\
\text { senbuch }\end{array}$ \\
\hline tapezieren & tapetować & obijać materiałem & (mit Stoff) überziehen \\
\hline die Schale & szalka od wagi & filiżanka & die Tasse \\
\hline
\end{tabular}


b) szwajcarsko-niemiecki

\begin{tabular}{|l|l|l|l|}
\hline \multicolumn{1}{|c|}{ Słowo } & $\begin{array}{c}\text { Znaczenie w stan- } \\
\text { dardzie niemieckim }\end{array}$ & $\begin{array}{c}\text { Znaczenie w stan- } \\
\text { dardzie szwajcar- } \\
\text { skim }\end{array}$ & $\begin{array}{c}\text { Niemiecki odpo- } \\
\text { wiednik wariantu } \\
\text { szwajcarskiego }\end{array}$ \\
\hline der Anzug & garnitur, ubranie & poszewka, powłoczka & der Bezug \\
\hline die Falle & pułapka, sidła & klamka do drzwi & die Türklinke \\
\hline der Rodel & saneczki wyczynowe & spis, lista & $\begin{array}{l}\text { das Verzeichnis, die } \\
\text { Liste }\end{array}$ \\
\hline das Rind & bydło, krowa & jałówka & die Färse \\
\hline der Schoppen & $\begin{array}{l}\text { lampka, } \\
\text { bombka, } \\
\text { kieliszek }\end{array}$ & $\begin{array}{l}\text { buteleczka dla dziec- } \\
\text { ka, jedzenie dla dziec- } \\
\text { ka w buteleczce }\end{array}$ & $\begin{array}{l}\text { die Säuglingsflasche, } \\
\text { das Essen in der Säu- } \\
\text { glingsflasche }\end{array}$ \\
\hline der Spatz & wróbel & $\begin{array}{l}\text { kawałek mięsa w zu- } \\
\text { pie }\end{array}$ & $\begin{array}{l}\text { Stück Fleisch in der } \\
\text { Suppe }\end{array}$ \\
\hline
\end{tabular}

W tym przypadku tłumacz staje przed dwoma problemami:

- rozpoznaniem wariantu narodowego,

- tłumaczeniem tego wariantu.

Warunkiem rozpoznania wariantu narodowego jest bardzo dobra znajomość języka i możliwość sprawdzenia w słownikach. Z tłumaczeniem na język polski jest tutaj podobnie jak w przypadku regionalizmów, natomiast w tłumaczeniu na język niemiecki możemy w przypadku listu do Austrii użyć austriacyzmu, a do Szwajcarii - helwetyzmu. Należy jednak uważać, by w tym samym liście/piśmie nie pojawiły się typowe teutonizmy, gdyż wówczas język ten będzie brzmiał nieco dziwnie. Takim teutonizmem nie tolerowanym przez Austriaków jest np. czasownik kucken/gucken.

W tym kontekście należy zwrócić uwagę na pozytywne efekty użycia wariantu austriackiego $\mathrm{w}$ pertraktacjach $\mathrm{z}$ biznesowymi partnerami austriackimi, nawet gdy są to elementy tego języka. Użycie austriacyzmów wywołuje pozytywne nastawienie do rozmówcy/partnera. Należy bowiem pamiętać o pewnym negatywnym nastawieniu Austriaków do mieszkańców Piefkinesien, czyli Piefkes, Piefkinesen, Saupreußen/Saupreißen, szczególnie zaś do języka zwanego Piefkinesisch, który nazywa się też Preußendeutsch, a nawet Saupreußisch/Saupreißisch. Dlatego też zaleca się zabranie z sobą tłumacza znającego choćby w ograniczonym stopniu wariant austriacki.

Znacznie więcej problemów mamy w tłumaczeniu oficjalnej terminologii. Trudności te pojawiają się zarówno w czasie tłumaczenia z języka polskiego na niemiecki, jak i odwrotnie. Jeżeli w pismach kierowanych do Austrii zastosujemy nomenklaturę niemiecką odbiegającą od austriackiej, możemy 
się liczyć z brakiem odpowiedzi lub przynajmniej złośliwymi uwagami i negatywnym nastawieniem do naszej sprawy. W przypadku Szwajcarii nie odczujemy tego tak wyraźnie, jednak nie świadczy to o tym, że Szwajcarom jest całkowicie obojętne, czy użyjemy teutonizmów zamiast helwetyzmów, czy nie. Faktem znacznie utrudniającym pracę tłumacza jest brak ogólnie dostępnej nomenklatury oficjalnej. W związku z tym poszczególne nazwy są różnie tłumaczone. Można odnieść wrażenie, że to poszczególni tłumacze decydują o formie odpowiedników polskich, a tak przecież nie powinno być, gdyż są to nazwy oficjalne. Można przyjąć, że polskie Ministerstwo Spraw Zagranicznych, Kancelarie Prezydenta i Premiera dysponują oficjalnymi listami nazw tych instytucji. Z list tych korzystają zapewne tzw. tłumacze rządowi.

Na początek kilka przykładów znalezionych w różnych źródłach tłumaczeń nazw austriackich, szwajcarskich i niemieckich:

a) pary austriacko-niemieckie

\begin{tabular}{|c|c|c|c|}
\hline Termin austriacki & $\begin{array}{l}\text { Odpowiedni } \\
\text { termin niemiecki }\end{array}$ & $\begin{array}{c}\text { Odpowiednik } \\
\text { polski dla austria- } \\
\text { cyzmu }\end{array}$ & $\begin{array}{l}\text { Odpowiednik } \\
\text { polski dla teutoni- } \\
\text { zmu }\end{array}$ \\
\hline der Bürgermeister & $\begin{array}{l}\text { der Bürgermeister, } \\
\text { Regierender Bürger- } \\
\text { meister }\end{array}$ & $\begin{array}{l}\text { mer (Wiedeń) } \\
\text { burmistrz (Inns- } \\
\text { bruck, Salzburg) }\end{array}$ & burmistrz \\
\hline $\begin{array}{l}\text { der Landeshaupt- } \\
\text { mann } \\
\text { die Landeshauptfrau }\end{array}$ & $\begin{array}{l}\text { der Ministerpräsi- } \\
\text { dent(in) im Land }\end{array}$ & $\begin{array}{l}\text { gubernator (guber- } \\
\text { natorka?) - nazwa } \\
\text { historyczna, myląca }\end{array}$ & $\begin{array}{l}\text { Premier Rządu Kra- } \\
\text { jowego }\end{array}$ \\
\hline der Nationalrat & der Bundestag & Bundestag & $\begin{array}{l}\text { Rada Narodowa - } \\
\text { też nieco mylące }\end{array}$ \\
\hline der Bundesrat & der Bundesrat & Rada Federalna & $\begin{array}{l}\text { Rada Związkowa, } \\
\text { Izba Związku, Bun- } \\
\text { desrat }\end{array}$ \\
\hline $\begin{array}{l}\text { die Bundes- } \\
\text { versammlung }\end{array}$ & $\begin{array}{l}\text { die Bundes- } \\
\text { versammlung }\end{array}$ & $\begin{array}{l}\text { Zgromadzenie } \\
\text { Związkowe, } \\
\text { parlament Austrii }\end{array}$ & $\begin{array}{l}\text { Zgromadzenie } \\
\text { Związkowe, } \\
\text { Parlament Związ- } \\
\text { kowy }\end{array}$ \\
\hline $\begin{array}{l}\text { der Obmann, die } \\
\text { Obfrau, (die Ob- } \\
\text { männin), der Be- } \\
\text { riebsobmann }\end{array}$ & $\begin{array}{l}\text { der/die Vorsitzende } \\
\text { der Vertrauen- } \\
\text { smann }\end{array}$ & $\begin{array}{l}\text { przewodniczący/ } \\
\text { /prezes, } \\
\text { mąż zaufania }\end{array}$ & $\begin{array}{l}\text { przewodniczący/ } \\
\text { /prezes, } \\
\text { mąż zaufania }\end{array}$ \\
\hline $\begin{array}{l}\text { der Landes- } \\
\text { parteiobmann }\end{array}$ & $\begin{array}{l}\text { der Parteichef im } \\
\text { Land }\end{array}$ & $\begin{array}{l}\text { przewodniczący } \\
\text { partii w kraju związ- } \\
\text { kowym/landzie }\end{array}$ & $\begin{array}{l}\text { przewodniczący } \\
\text { partii w kraju związ- } \\
\text { kowym, landzie }\end{array}$ \\
\hline
\end{tabular}




\begin{tabular}{|l|l|l|l|}
\hline die Statutarstadt & kreisfreie Stadt & $\begin{array}{l}\text { miasto na prawach } \\
\text { powiatu }\end{array}$ & $\begin{array}{l}\text { miasto na prawach } \\
\text { powiatu }\end{array}$ \\
\hline
\end{tabular}

b) pary szwajcarsko-niemieckie

\begin{tabular}{|l|l|l|l|}
\hline Termin szwajcarski & $\begin{array}{c}\text { Odpowiedni ter- } \\
\text { min niemiecki }\end{array}$ & $\begin{array}{l}\text { Odpowiednik pol- } \\
\text { ski dla helwetyzmu }\end{array}$ & $\begin{array}{l}\text { Odpowiednik pol- } \\
\text { ski dla teutonizmu }\end{array}$ \\
\hline der Bundesrat & $\begin{array}{l}\text { die Bundesregie- } \\
\text { rung }\end{array}$ & $\begin{array}{l}\text { Rada Związkowa, } \\
\text { Rada Federacyjna }\end{array}$ & Rząd Federalny \\
\hline der Nationalrat & der Bundestag & Rada Narodu & Bundestag \\
\hline der Ständerat & der Bundesrat & Rada Rantonów & $\begin{array}{l}\text { Rada Związkowa, } \\
\text { Bundesrat }\end{array}$ \\
\hline $\begin{array}{l}\text { die Bundesversam- } \\
\text { mlung }\end{array}$ & $\begin{array}{l}\text { die Bundesversam- } \\
\text { mlung }\end{array}$ & $\begin{array}{l}\text { Zgromadzenie Fe- } \\
\text { deralne }\end{array}$ & $\begin{array}{l}\text { Zgromadzenie } \\
\text { Związkowe }\end{array}$ \\
\hline $\begin{array}{l}\text { der Bundespräsi- } \\
\text { dent }\end{array}$ & $\begin{array}{l}\text { der Bundespräsi- } \\
\text { dent }\end{array}$ & $\begin{array}{l}\text { Prezydent Konfede- } \\
\text { racji Szwajcarskiej }\end{array}$ & Prezydent Federalny \\
\hline
\end{tabular}

$\mathrm{Na}$ koniec jeszcze jedna uwaga. Otóż oficjalny standard austriacki i oficjalny standard szwajcarski nie używają pewnych słów/określeń. Przykładem może być Fräulein. W Austrii, podobnie jak w Polsce, w rozmowach używa się obowiązkowo stopni i tytułów naukowych, w Niemczech od 1968 raczej nie:

\section{Sehr geehrter Professor Szulc Sehr geehrter Herr Szulc}

Tłumacząc więc z języka polskiego na wariant austriacki, zachowujemy obowiązkowo tytuł, natomiast w przypadku tłumaczenia na wariant niemiecki niekoniecznie. Tłumacząc $\mathrm{z}$ wariantu niemieckiego na polski, musimy tytuł dodać. Odwrotnie ma się sprawa $\mathrm{z}$ tytułami szlacheckimi. W Austrii zniesiono ich używanie po I wojnie światowej, w Niemczech są one zgodnie z ustawą $\mathrm{z}$ roku 1928 składnikiem nazwiska rodowego.

Tłumaczenie z wariantu enerdowskiego nie sprawia trudności, gdyż w Polsce przed rokiem 1989 funkcjonowała w zasadzie identyczna terminologia:

\begin{tabular}{|l|l|}
\hline \multicolumn{1}{|c|}{ Termin enerdowski } & \multicolumn{1}{c|}{ Termin polski } \\
\hline der Generalsekretär & Sekretarz Generalny \\
\hline der Vorsitzende des Staatsrates & Przewodniczący Rady Państwa \\
\hline der Erste Sekretär des ZK & I Sekretarz KC \\
\hline das Politbüro & Biuro Polityczne \\
\hline das Zentralkomitee & Komitet Centralny \\
\hline
\end{tabular}




\begin{tabular}{|l|l|}
\hline die Bezirksleitung & Komitet Wojewódzki \\
\hline der Staatsrat & Rada Państwa \\
\hline
\end{tabular}

Podsumowując nasze rozważania, należy stwierdzić:

- nie ma w zasadzie bezpośredniej możliwości przetłumaczenia wyrażeń gwarowych i ponadgwarowych regionalizmów, nawet gdy są one użyte w celu stylizacji,

- należy zwrócić uwagę, czy w przypadku tłumaczenia standardu austriackiego bądź szwajcarskiego poszczególne słowa nie mają innego znaczenia niż w standardzie niemieckim (swego rodzaju fałszywi przyjaciele tłumacza),

- w przypadku tłumaczenia listów i pism oficjalnych do Austrii należałoby stosować w ramach możliwości standard austriacki, gdyż dzięki temu osiągniemy $z$ reguły lepszy efekt.

W przypadku Szwajcarii jest to mniej ważne i to z trzech przyczyn:

- oficjalny wariant szwajcarski nie jest tak dobrze rozbudowany,

- w korespondencji oficjalnej używa się często języka francuskiego;

- w przypadku listów oficjalnych należy używać nomenklatury stosowanej w danym standardzie/wariancie narodowym, gdyż np. używanie tytulatury niemieckiej w pismach do Austriaków spotyka się $\mathrm{z}$ niechęcią.

\section{Literatura}

Back, O., Benedikt, E., Blüml, K., Ebner, J., Hornung, M., Möcker, H., Pohl, H.-D., Tatzreiter, H., 2009, Österreichisches Wörterbuch Schulausgabe, Wien.

Clyne, M., red., 1992, Pluricentric Languages, Berlin-New York.

Ebner, J., 1998, Wie sagt man in Österreich, Mannheim-Leipzig-Wien-Zürich.

König, W., 1998, dtv-Atlas Deutsche Sprache, München.

Meyer, K., 1989, Wie sagt man in der Schweiz, Mannheim-Leipzig-Wien-Zürich.

Pisarek, W., 1992, „Regionalizm”, [w:] Encyklopedia języka polskiego, Wrocław-Warszawa-Kraków, s. 283.

Saloni, Z., 2003, „Regionalizm (prowincjonalizm)”, [w:] Encyklopedia językoznawstwa ogólnego, Wrocław-Warszawa-Kraków, s. 485. 


\section{Regionalisms in translation on the basis of translations from German into Polish Summary}

The article discusses problems related to translating regionalisms (dialects, extradialectal regionalisms, standards of national varieties in pluricentric languages). Pluricentric languages are languages with more than one national standard variety, e.g. English or German. Dialectal expressions and extradialectal regionalisms must be translated into the standard target language. Translating into a dialect is not an option, since Bavarian is not to become Silesian. A slightly different approach should be adopted when rendering from and into standard national languages. The names of Austrian institutions should be different in Polish from the names of German or Swiss institutions. In case of translation from the Austrian variety into Polish one must analyze words whose meaning in this variety is to be different from those in the German variety, i.e. false friends. When translating documents addressed to Austria in general or Austrian institutions it is recommended that one should write in accordance with standards adopted there. This is due to the fact that both using Austrian terminology and avoiding typical Germanisms are welcome. 